\title{
A REFERENCE MODEL IN BPMN FOR CONCEPTUAL MODELLING OF MASTER PLANNING SCHEDULE
}

\author{
Tulio Cremonini Entringer \\ Universidade Estadual do Norte Fluminense Darcy Ribeiro, Brazil \\ E-mail: tulio_entringer@hotmail.com
}

Ailton da Silva Ferreira Universidade Federal Fluminense - UFF, Brazil E-mail: ailtonsilvaferreira@yahoo.com.br

Submission: 5/24/2019 Accept: 6/4/2019

\section{ABSTRACT}

Companies are progressively investing in practices aimed at improving the quality of management, with the main purpose of enabling them to operate competitively in the present market. For this, it is necessary to document the activities and information of the existing business processes in the organization, aiming at reducing time and cost in the elaboration of the particular model. In this context, the objective of this work is to develop a reference model of the Master Production Schedule (MPS) processes, an important module of production planning and control (PPC). The research methodology used in this work was divided into the following stages: study of MPS and business process modeling, definition of reference model processes, choice of methodology and process modeling tool, development of reference model and prototype of the software and, finally, analysis of results. The modeling notation used was the BPMN, since it is considered a standard language in the field of process modeling. The prototype was developed through the Delphi interface in order to apply the model to support the implementation of business management programs. As results, from a formal documentation, the model proved to be a useful mechanism in the understanding of the processes raised and appropriate in the support to the implantation of production management tools.

Keywords: Reference Model; Production Planning and Control; Master Production Schedule; BPMN 
ISSN: $2236-269 X$

DOI: 10.14807/ijmp.v11i2.1067

\section{INTRODUCTION}

The organizations are progressively investing in practices aimed at improving the quality of management, with the main purpose of enabling them to act competitively in the present market, such as: reengineering processes, adoption of an integrated business management system (ERP), ISSO (International Organization for Standardization) certifications, lean production, costing by activities, among others. However, the great majority of improvement actions demand a high investment, causes changes in the company's behavior and some of them have a high cost and long implementation period, for example in the adoption of ERP (BREMER; LENZA, 2000; CORREA; SPINOLA, 2015).

A common aspect when adopting an action aimed at improving the quality of business management is that most of them require that the activities, information and resources of the processes carried out by the company be lifted and documented, that is, Business processes in the organization.

However, the business process modeling activity is still not a common practice among organizations (THURER; FILHO, 2012), which contributes to the increase in cost and time of implementation of the system or improvement projects, due to the need to develop new models related to their Business Processes (BREMER; LENZA, 2000). If companies already had a reference model, this activity would not be necessary. According to Scheer (2000), case studies have shown that the use of reference models can reduce the cost and time of implementation of organizational projects by up to $30 \%$.

In the business context, one of the most important business processes for organizations is Production Planning and Control (PPC). This process is responsible for surveying demand, production planning, capacity planning, materials management, production scheduling, etc. (FERNANDES; GODINHO FILHO, 2010; MUKHOPADHYAY, 2013).

Among the basic concepts of the hierarchy of the PPC function, referring to Material Planning, we highlight the Master Production Schedule (MPS). According to (VIEIRA; FAVARETTO, 2006), MPS is a decisive key activity, in which the strategic objectives of business planning are converted into an anticipated plan of production, from which the other schedules at lower levels are derived.

According to Thurer and Filho (2012), most companies, especially small and mediumsized companies, are aware that they must improve their PPC activities in order to obtain lead time and work in process reductions and achieve greater operational efficiency. However, for 
DOI: 10.14807/ijmp.v11i2.1067

the authors, organizations simply do not know how to do this, since the vast majority of research and solutions for PPC are focused on large and complex companies.

Finally, there is a great and growing attention, both from the academic and business environments, in the development of models that support the planning of entrepreneurial resources (CORREA; SPINOLA, 2015). However, studies found in the literature directed to the development of PPC models are mostly focused on particular industrial segments and that address modules of specific production management activities.

In order to support companies, especially small and medium enterprises, in the development and implementation of business management improvement actions, the present work aims at the development of a reference model that addresses Business Processes related to MPS activities.

In addition, this work also aims to develop a software prototype through the Delphi interface (Object-Pascal language) in order to apply the reference model to support the implementation of enterprise management systems.

The article is organized as follows: section 2 discusses the literature review regarding reference model and MPS; section 3 presents the methodological procedures used in this study; section 4 presents the results obtained; and finally, section 5 presents the final considerations.

\section{REFERENCE MODEL}

Reference modeling is defined as the process of formally documenting a problematic domain in order to understand and communicate stakeholders (SIAU, 2004; SIAU; ROSSI, 2011).

The reference models, which can be developed in real situations or in theoretical studies, document the various aspects of a business process (BREMER; LENZA, 2000). According to Scheer (2000), one can distinguish between procedural models or standard software implementation, and business models such as models for production management and product development.

For Vernadat (1996), a reference model must contain a certain degree of generality and be customizable. Therefore, it should serve as a basis for discussion, a formal or semiformal suggestion for the elaboration of specific models, bringing information regarding the design of a business process. Keller and Teufel (1998) understand that reference models can be applied 
DOI: 10.14807/ijmp.v11i2.1067

in cases of accumulated experience in a business type, and in business process solutions implemented and executed in business management software.

Vojislav and Leon (2000) propose that the right choice of reference models helps to minimize possible errors in the early phases of modeling and implementation of management systems. This allows the design of a process or system to begin with the appropriate choice of requirements and also with the establishment of appropriate characteristics given by the reference model.

According to Bremer and Lenza (2000), the objective of the reference model is to provide the company with an initial solution for its Business Processes, so that, through this, the particular model of the company can be specified and detailed. According to Climent, Mula and Hernández (2009), reference models are useful in describing and graphically depicting important aspects of a particular process, distinguishing, for example, people, departments, and the link between them. Additionally, Vergidis, Turner and Tiwari (2008) models adequately portray and represent processes, emphasizing those aspects that need to be communicated and addressed.

Bolloju and Leung (2006) suggest that during the analysis phase of an information system development, the conceptual model can be used to capture and represent the development and deployment requirements of such technologies. For Scheer (2000), the use of reference models can reduce the cost and time of implementation of organizational projects, for example in the adoption of ERP.

In a review elaborated by Hernandez, Mula and Ferriols (2008), it was proposed that a reference model describe the social and physical aspects of the world in order to understand and communicate. In addition, it was also described that the reference model should go beyond the terms "specifications" and "requirements" and apply three linguistic concepts (syntax, semantics and pragmatics) to four aspects of modeling: language, domain, model and participants.

In summary, according to Vernadat (2003), the advantages of adopting reference models are to reduce time and cost in the development of the particular model; comparing the activities of the company with the activities proposed in the model, that is, best practices; and better support in deploying integrated enterprise management systems.

The model to be developed in this work will give greater emphasis to the information and activities that compose the PPC process, because its main objective is support in the 
DOI: 10.14807/ijmp.v11i2.1067

implementation of organizational improvements, such as business management systems (Figure 1).

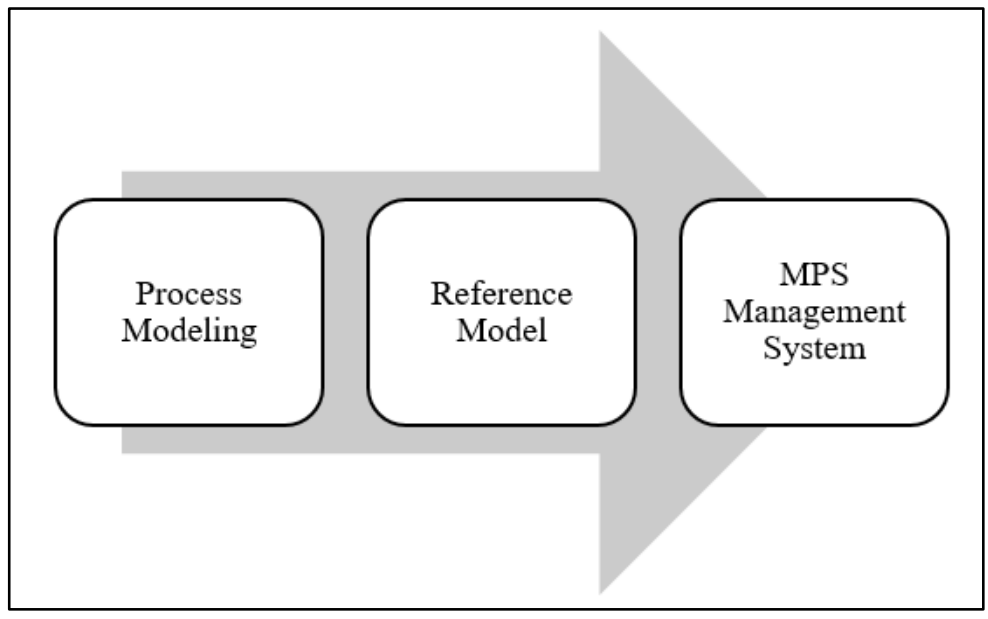

Figure 1: Process of elaboration of the reference model. Source: author.

\section{MASTER PRODUCTION SCHEDULE}

The Master Production Schedule is elaborated from the discretization of the demand of each period of the aggregate production planning in smaller periods and the breakdown of production into groups of individual products or products (GAITHER; FRAZIER, 2005).

According to Vieira and Favaretto (2006), MPS is a decisive key activity in which the strategic objectives of business planning are converted into an anticipated plan of production, from which all other programming at lower levels is derived.

For Jonsson and Ivert (2015), MPS is the process of developing plans to identify which quantities of products are to be manufactured during certain periods, conducting operations in terms of what is assembled, manufactured and purchased. According to the authors, MPS also provides sales information regarding what can be promised to customers and when deliveries can be made, which makes the method a vital link between customer order management and production.

Thus, it is observed that a recurring task encountered by manufacturing companies concerns the development of the MPS in which the schedules and production quantities for each of the final items are determined over a prespecified time horizon. For As'ad and Demirli (2010), MPS's mission is to translate market requirements into a deployable production plan that efficiently uses the available resources while maintaining the associated costs to a minimum. 
INDEPENDENT JOURNAL OF MANAGEMENT \& PRODUCTION (IJM\&P)

http://www.ijmp.jor.br

v. 11, n. 2, March-April 2020

ISSN: 2236-269X

DOI: 10.14807/ijmp.v11i2.1067

Lalami, Frein and Gayon (2015) point out that the objective of the MPS process is to provide, for each production line, the quantity to be produced of each product reference in the planning horizon. MPS is usually carried out over a medium-term horizon and is based on estimated or known demands (ENGLBERGER; HERRMANN; MANITZ, 2016). Since the demands are not known throughout the planning horizon, in most applications, planning is based on demand forecasts, through the planning of production orders, and can be performed by the aggregate plan. This process is supported by the verification of resource availability through the approximate capacity planning (OLHAGER, 2013).

Establishing a stable MPS to facilitate manufacturer and supplier integration is a major issue in supply chains based on Material Requisition Planning (MRP), discussed in the next topic. Due to imperfect information on future demand, it is common practice for manufacturers to plan production quantities continuously by solving a static batch sizing model within a specific planning horizon using currently available information. Over time, a subset of the first replenishment decisions is implemented, and then the plan is updated using demand data collected since the last planning iteration (SAHIN; POWELL ROBINSON; GAO, 2008).

Thus, it can be stated that the MPS is the part of the executable planning in the medium term, defining how much will be produced of each product disaggregated of the family of products and how much of inventory will generate in this planning horizon. Disaggregation factors are resources used by the company to adjust production to demand; thus, it may vary according to the convenience of the organization's strategy (CORRÊA; CORRÊA, 2012).

It is during this stage of planning that the manufacturing orders are issued. Moreira (2008) points out that the MPS establishes a sequence of which products should be made and on what dates, incorporating information on demand forecasting, security stock, size of manufacturing lots, etc.

Four approaches to MPS can be adopted: make-to-order production; assembly-to-order; make-to-stock; and engineer-to-order. The difference between the approaches lies in the possibility of using inventories to balance demand and supply, using inventory to reduce the lead time of deliveries. It should be noted that more than one production strategy can be used in a company, especially when the MPS logic part does not fit with its strategy (WATTANAPORNPROM; LI, 2013). It should be noted that managers working with the Make to Order policy must ensure the simultaneous availability of all the parts needed for production, as any unavailability may cause delays in completion time. A major challenge of the Make to 
INDEPENDENT JOURNAL OF MANAGEMENT \& PRODUCTION (IJM\&P)

http://www.ijmp.jor.br

v. 11, n. 2, March-April 2020

ISSN: 2236-269X

DOI: 10.14807/ijmp.v11i2.1067

Order approach operating under high demand variability is to produce customized parts in time to meet internal production schedules.

Facing this situation, Teo, Bhatnagar and Graves (2012) conducted a case study of an offshore oil platform producer that highlights the main aspects of these problems. Scholars have considered two key tactical parameters for solving adversity: the MPS time window and the planned lead time of each workstation. This improvement effort reduced the cost of subcontracting by implementing several actions: creating a master schedule for each item family, aligning the master schedule in its planning window, and controlling the production at each workstation by the lead time planned.

In this scenario it is highlighted that the schedule of the MPS can influence the costs of production. Gahm, Dünnwald and Sahamie (2014) present an MPS approach, in which there are two time cost drivers. First, the long assembly times combined with high product values, which result in high capital commitments. Second, contractual penalties and compensation costs arise if the confirmed delivery dates can not be maintained. In this way, it is verified that the lead time needs to be minimized and the manufacturing schedule must be considered when calculating the MPS, since it can significantly influence the resulting delivery times.

In addition to defining the final items that must be produced, the MPS also aims to avoid overloading or generating idle production, so that productive resources are used efficiently (GAITHER; FRAZIER, 2005).

One of the main factors affecting the performance of MPS is the fluctuation of demand, which implies frequent updates of the information needed for decision making, causing instability. As a result, overall cost deteriorates and productivity decreases. Facing this problem, Herrera, Belmokhtar-Berraf, Thomas and Parada (2016) proposed a programming model that aims to provide a set of plans in order to guarantee a compromise between production cost and production stability. The experimental study highlighted that the procedure produces a set of plans that, in practice, would allow flexible production management.

Possible changes in the demands already confirmed in the short run are costly and bring planning inconvenience, as they are usually the last minute requests that cause disruption throughout a company's planning system. Thus, the master plan is revised and updated according to the demand, generating new values (Herrera et al., 2016). If the demand is very divergent, the aggregate plan can also be updated, generating a new master plan. Only after the demand values are adequate, is the master plan considered viable and implemented. 
DOI: 10.14807/ijmp.v11i2.1067

Jonsson and Ivert (2015) emphasize, as observed in Figure 2, that the MPS consists of the following activities: forecasting future demand, generating a preliminary production plan, adapting plans as needed, reconciling the plans developed and the conditions for their implementation, and establishing prepared plans.

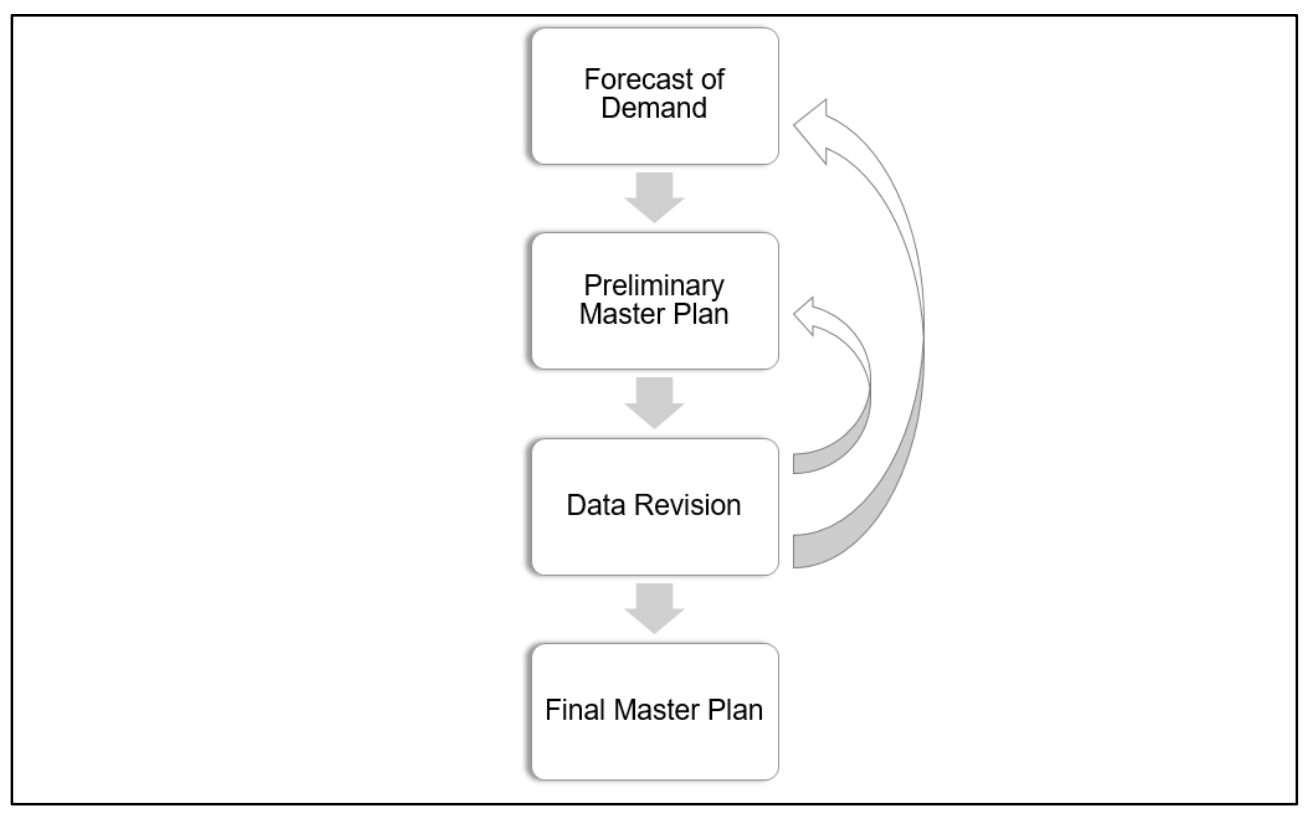

Figure 2: Process of validation of the production master plan.

Source: adapted from Jonsson \& Ivert (2015).

In this way, it is observed that the master plan consists of a basic reference for the good progress of production to establish when and in what quantity each product should be produced within a certain planning horizon. Once the MPS has been developed and validated, you move on to the next stage of production planning: MRP. In this step, it will be calculated, based on the basic record of the MPS, what the need for materials, components and capacities needed to achieve the plans.

\section{RESEARCH METHODOLOGY}

\subsection{Definition of research method}

The reference model was developed from theoretical studies. Thus, this research uses the procedures of bibliographic research, since it was developed from previous works such as dissertations, articles and books on the subject matter. In this way, the future work can be based on the conclusions presented in this article, and elaborate hypotheses aiming to deepen the study on the subject or related specific aspects.

On the other hand, this research can also be classified as experimental, since it is based on the creation of a reference model of a Production Planning and Control system, modeled 
DOI: 10.14807/ijmp.v11i2.1067

through software. Thus, with the objective of developing a reference model and exposing the way it was developed from the analysis of the activities involved in the processes, allow this work to be classified as a descriptive research.

\subsection{Scope of research}

The phase of process identification and hierarchization levels is considered the key step in process modeling, aiming to identify all existing Business Processes in a particular activity of an organization. Figure 3 presents the model of the PPC process hierarchy relating the planning of the capacity of its resources with the planning of the needs of its materials. The hierarchical decomposition of the PPC function starts from understanding the basic concepts related to material planning levels, namely: Sales \& Operations Planning (S\&OP) and Aggregate Planning (AP); Master Production Planning (MPS); Material Requirements Planning (MRP) and Production Schedule (PS) (CORRÊA; CORRÊA, 2012; MUKHOPADHYAY, 2013).

This work will be limited in the development of the MPS reference model and its respective capacity planning. The modules of the Production Planning and Control function related to Capacity Planning are Resource Requirements Planning (RRP), Rough Cut Capacity Planning (RCCP) and Capacity Requirements Planning (CRP).

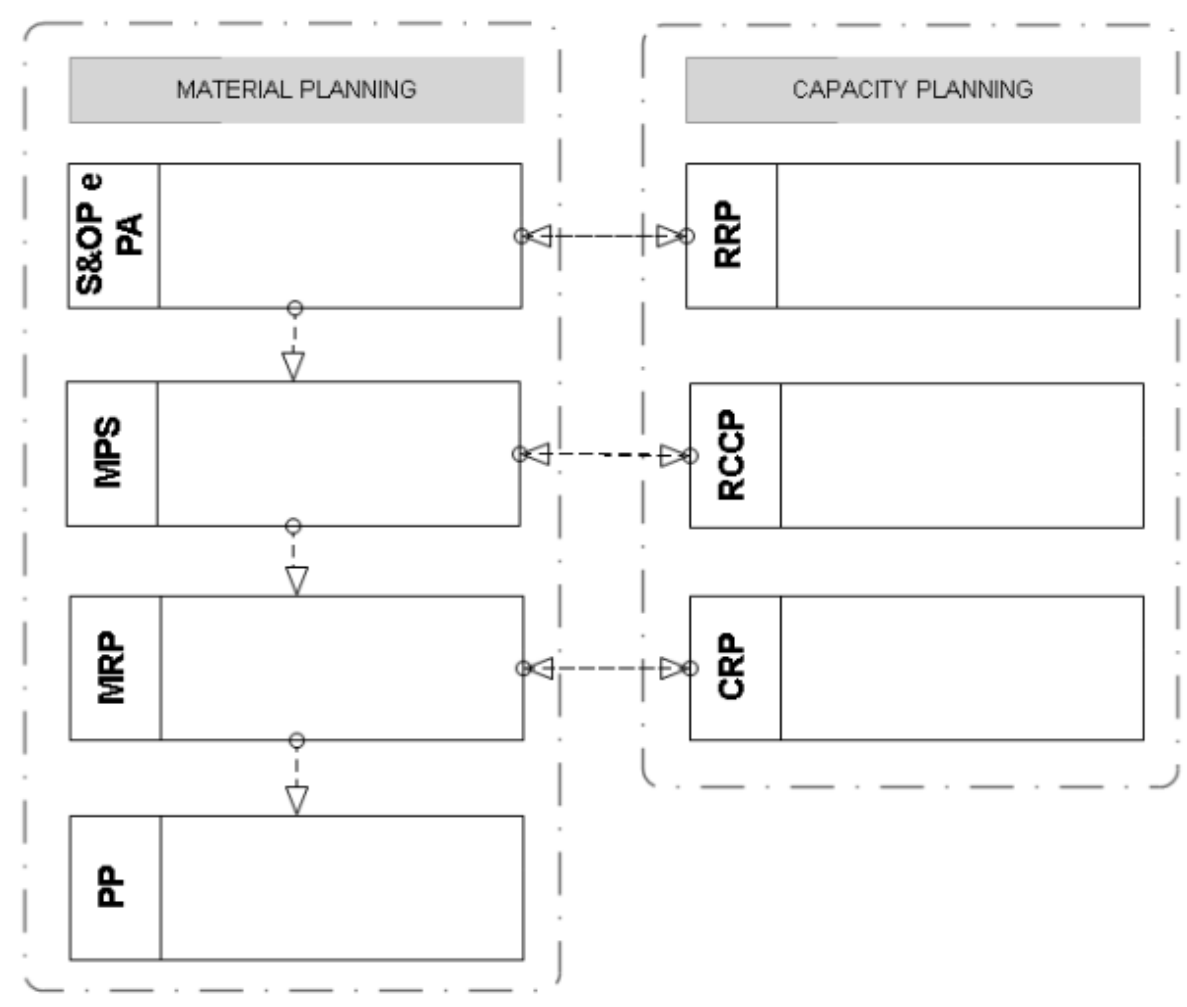

Figure 3: Hierarchy of production planning and control. Source: author. 
ISSN: $2236-269 X$

DOI: 10.14807/ijmp.v11i2.1067

\subsection{Stages of research methodology}

The methodology used for the elaboration of this work was divided into eight sequential stages, as shown in Figure 4.

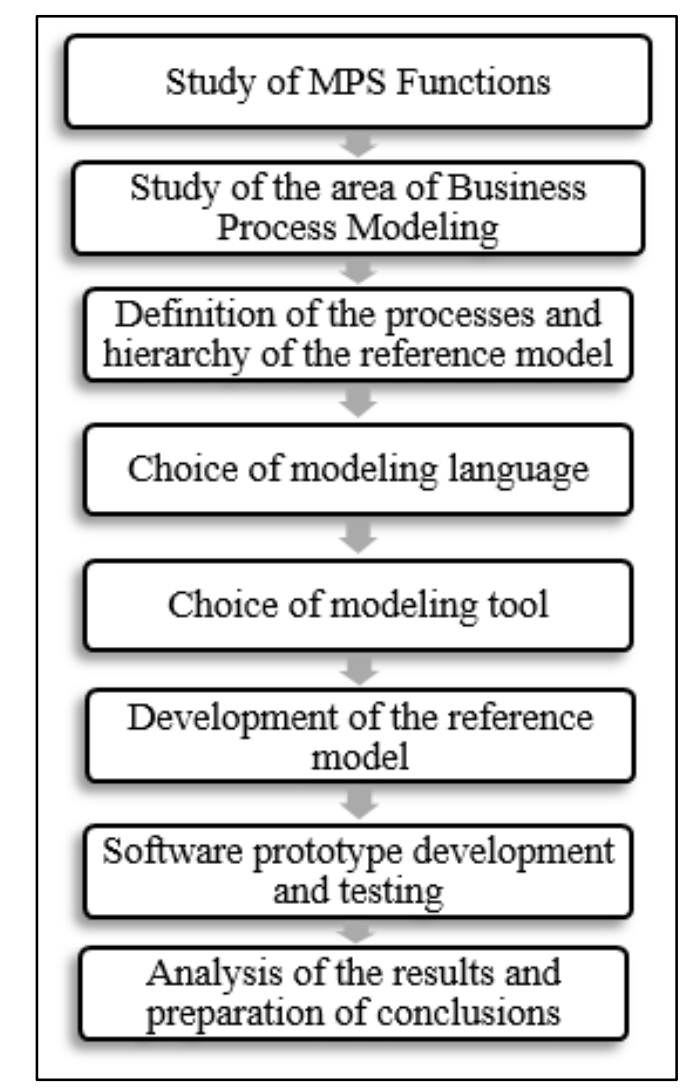

Figure 4: Stages of research methodology. Source: author.

- Stage I - Study of Production Planning and Control Functions: In this step, according to the bibliographical references related to the topic of study, concepts, activities and information and functions of a typical hierarchy of production planning were raised and studied;

- Step II - Study of the Business Process Modeling area: In the second stage, the concepts and languages regarding process modeling, as well as reference models, were studied and analyzed from the scientific literature;

- Step III - Definition of the processes and hierarchy of the reference model: In this third stage, after the phases of the bibliographic review, the processes and hierarchy were defined that will compose the reference model of an MPS system; 
DOI: 10.14807/ijmp.v11i2.1067

- Step IV - Choice of the modeling language: In this fourth stage, the modeling language used for the development of the reference model was defined. The modeling notation selected was BPMN;

- Step V - Choice of the modeling tool: In this step, the modeling tool was defined, in order to provide facilities in the understanding and visualization of the model, that is, the full understanding of the functions of a system. The modeling tool selected was Bizagi Process Modeler version 3.1.0.011;

- Step VI - Development of the reference model: In this step, based on the language and defined modeling tools, the reference model of an MPS system was developed, based on theory and BPMN notation;

- Step VII - Development of application software and tests: In the seventh stage, once the reference model of the MPS system was elaborated, a software prototype was developed with the purpose of applying and validating the model, from the interface Delphi version 7.0, which used the Object-Pascal language;

- Step VIII - Analysis of the results obtained and conclusions drawn: In the last step, the results presented in the previous phases were analyzed and discussed, as well as the conclusions obtained and suggestions for future work.

\section{RESULTS AND DISCUSSION}

\subsection{MPS modeling}

The MPS is organized, in short, from the discretization of the demand of each period of the aggregate planning of production in smaller periods and the breakdown of the production into groups of individual products or products. In addition, this planning is aimed at developing plans that define the quantities of products that must be manufactured during certain periods.

The input and output information required to construct the reference model of the MPS module are shown in Table 1. 
INDEPENDENT JOURNAL OF MANAGEMENT \& PRODUCTION (IJM\&P)

http://www.ijmp.jor.br

v. 11, n. 2, March-April 2020

ISSN: 2236-269X

DOI: 10.14807/ijmp.v11i2.1067

Table 1: 1 MPS information.

\begin{tabular}{|l|l|}
\hline Input & Output \\
Products disaggregated & Production master plan \\
Medium-term planning period & Projection of inventories of disaggregated products \\
Disaggregation factor & \\
Lot sizes & \\
Scheduled receipts & \\
Initial inventories of disaggregated products & \\
Medium-term capacity plan & \\
\hline
\end{tabular}

Source: author

The activities related to this module of the PPC planning are presented, with their respective theoretical references, in Table 2.

Table 2: Sequence of activities related to the MPS.

\begin{tabular}{|c|c|c|}
\hline \# & Activity & Theoretical Framework \\
\hline 1 & $\begin{array}{l}\text { Disaggregation of the items related to the sales plan from the } \\
\text { aggregate plan (family of products). }\end{array}$ & $\begin{array}{l}\text { (CORRÊA; CORRÊA, 2012; } \\
\text { CORRÊA; GIANESI; CAON, } \\
\text { 2009; GAITHER; FRAZIER, 2005; } \\
\text { VOLLMANN, 2005) }\end{array}$ \\
\hline 2 & Definition of the medium term planning period. & $\begin{array}{l}\text { (CORRÊA; CORRÊA, 2012; } \\
\text { ENGLBERGER et al., 2016; } \\
\text { LALAMI et al., 2015) }\end{array}$ \\
\hline 3 & $\begin{array}{l}\text { Calculation of the disaggregated production, based on the } \\
\text { disaggregation factors. }\end{array}$ & $\begin{array}{l}\text { (CORRÊA; CORRÊA, 2012; } \\
\text { GAITHER; FRAZIER, 2005; } \\
\text { TUBINO, 2007) }\end{array}$ \\
\hline 4 & $\begin{array}{l}\text { Definition of the production lot size of each disaggregated } \\
\text { product. }\end{array}$ & $\begin{array}{l}\text { (CORRÊA; CORRÊA, 2012; } \\
\text { CORRÊA et al., 2009) }\end{array}$ \\
\hline 5 & $\begin{array}{l}\text { Survey of the initial stocks and the level of security stocks of } \\
\text { each disaggregated product. }\end{array}$ & $\begin{array}{l}\text { (CORRÊA; CORRÊA, 2012; } \\
\text { MOREIRA, 2008) }\end{array}$ \\
\hline 6 & Survey of scheduled receipts over the planning period. & (CORRÊA; CORRÊA, 2012) \\
\hline 7 & Calculation of the master plan output. & $\begin{array}{l}\text { (CORRÊA; CORRÊA, 2012; } \\
\text { CORREAA et al., 2009; JONSSON; } \\
\text { IVERT, 2015; MOREIRA, 2008; } \\
\text { VOLLMANN, 2005) }\end{array}$ \\
\hline 8 & Calculating Projected Stock. & $\begin{array}{l}\text { (CORRÊA; CORRÊA, 2012; } \\
\text { VOLLMANN, 2005) }\end{array}$ \\
\hline 9 & Issuance of the master plan & $\begin{array}{l}\text { (CORRÊA; CORRÊA, 2012; } \\
\text { CORRÊA et al., 2009; MOREIRA, } \\
\text { 2008; VOLLMANN, 2005) }\end{array}$ \\
\hline 10 & Review the production master plan if necessary. & $\begin{array}{l}\text { (JONSSON; IVERT, 2015; } \\
\text { TUBINO, 2007) }\end{array}$ \\
\hline
\end{tabular}

Source: author

The proposed MPS model (Figure 5) initially provides the definition of disaggregated products from the product family established in the S\&OP/AP stage.

Then, according to the proposed model, the definition of the planning period (medium term) is carried out, and this time period must come from the period that was also established in the planning stage prior to the MPS, S\&OP/AP.

From a database, for example a demand history of the products belonging to the family of products under analysis, the disaggregation factors of the products are defined, in order to 
DOI: 10.14807/ijmp.v11i2.1067

calculate the disaggregated production of each of these products, resulting in a with a description of the production demand of the products.

Then, for the calculation of the master production, it is necessary, besides the information contained in the disaggregated plan, also the survey of the sizes of the production batches, the level of security stocks and the programmable receipts, the latter if any. In this step, for the calculation of the master production, it is also necessary to establish information about the projected inventories of the products, especially the projected inventories of the time period prior to the current planning period (remaining stock). It is worth mentioning that, for the establishment of MPS production levels, it is necessary to obtain information from the RCCP regarding the medium-term productive capacity.

After the consolidation of the production plan, the projected inventories are calculated, specifically the inventories referring to the current planning period. In this step, the initial stock of the product is taken into account before planning begins.

Finally, after the establishment of the projected production plan and inventory, the master production plan is issued. In case of need, it is possible to carry out a review of this plan elaborated. After review, the consolidated MPS plan is issued.

This information is required for the calculation of the capacity plan (RCCP), as well as for the analysis and definition of the MRP.

The reference model, in BPMN notation, referring to the MPS module is shown in Figure 5. The model for Rough Cut Capacity Planning (RCCP), which aims to support MPS decisions, will be described below. 
ISSN: 2236-269X

DOI: 10.14807/ijmp.v11i2.1067

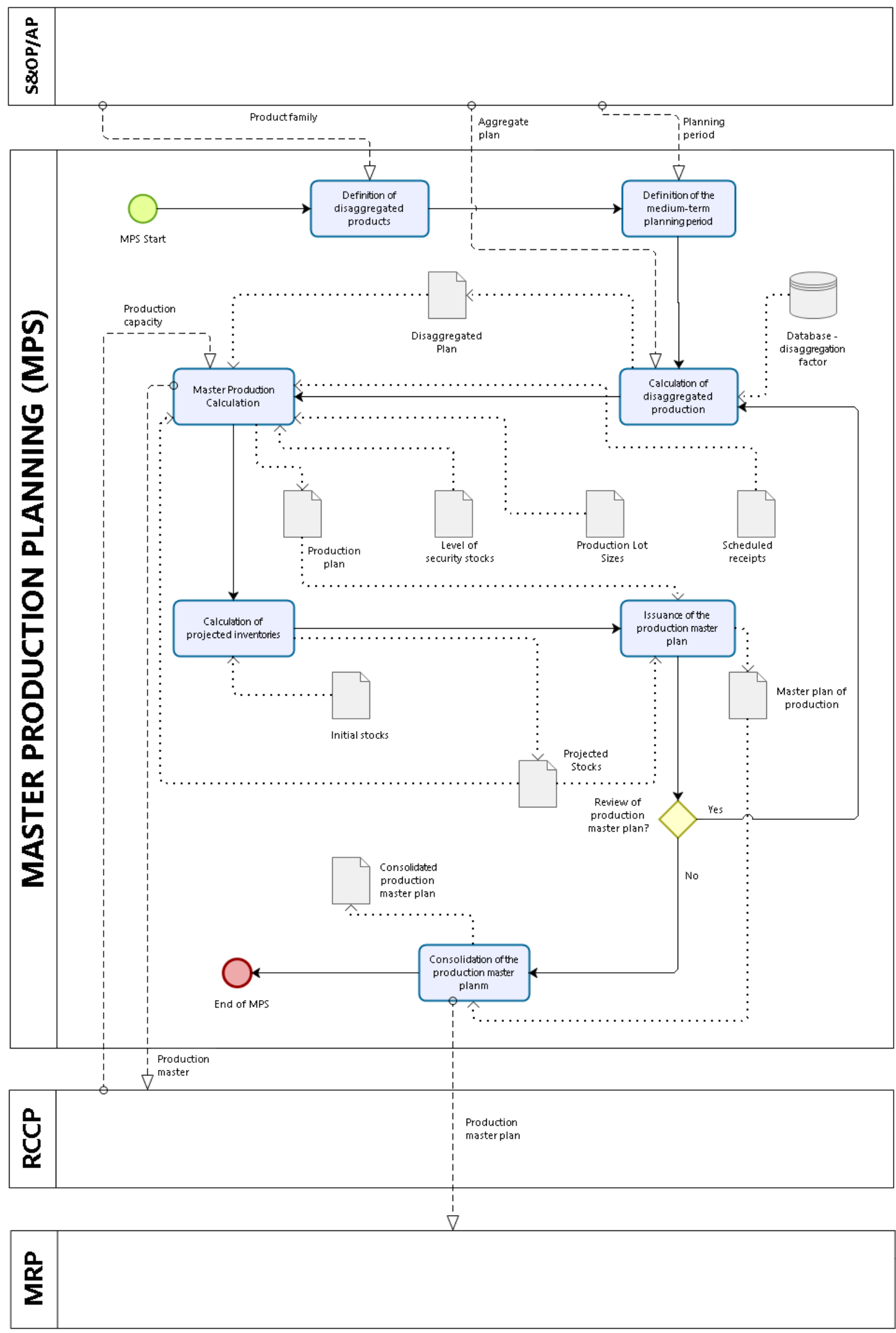

Figure 5: Modeling of MPS in BPMN.

Source: author. 
INDEPENDENT JOURNAL OF MANAGEMENT \& PRODUCTION (IJM\&P)

http://www.ijmp.jor.br

v. 11, n. 2, March-April 2020

ISSN: 2236-269X

DOI: 10.14807/ijmp.v11i2.1067

\subsection{RCCP modeling}

The RCCP is intended to support MPS decisions. This planning aims to generate a plan of production of final products that is approximately feasible and to subsidize the decisions of how much to produce of each product, mainly in the situations of limitation in which, by limitation of capacity of some resources, it is not possible to produce all the desired volume to meet production plans.

The input and output information required to compile the RCCP module reference model are shown in Table 3.

Table 3: RCCP information.

\begin{tabular}{|l|l|}
\hline \multicolumn{1}{|c|}{ Input } & \multicolumn{1}{|c|}{ Output } \\
\hline Products disaggregated & Capacity required \\
Medium-term planning period & Capacity installed \\
Working days & Charging rate \\
Daily working day & Medium-term production capacity plan \\
Amount of labor & \\
Quantity of subcontracted labor & \\
Overtime of daily work & \\
Setup times & \\
Production rates & \\
Master production & \\
\hline
\end{tabular}

Source: author

The activities related to this module of the PPC planning are presented, with their respective theoretical references, in Table 4.

Table 4: Sequence of activities related to the RCCP.

\begin{tabular}{|c|c|c|}
\hline \# & Activity & Theoretical Framework \\
\hline 1 & Definition of the disaggregated products specified in the MPS. & $\begin{array}{l}\text { (CORRÊA; CORRÊA, 2012; } \\
\text { CORRÊA et al., 2009; GAITHER; } \\
\text { FRAZIER, 2005; VOLLMANN, } \\
\text { 2005) }\end{array}$ \\
\hline 2 & Definition of the planning period specified in the MPS. & $\begin{array}{l}\text { (CORRÊA; CORRÊA, 2012; } \\
\text { MUKHOPADHYAY, 2013; } \\
\text { OLHAGER; RUDBERG; } \\
\text { WIKNER, 2001; VOLLMANN, } \\
\text { 2005). }\end{array}$ \\
\hline 3 & $\begin{array}{l}\text { Survey of the following information regarding productive capacity: } \\
\text { quantity of labor (normal and subcontracted). }\end{array}$ & \multirow{3}{*}{$\begin{array}{l}\text { (CORRÊA; CORRÊA, 2012; } \\
\text { CORRÊA et al., 2009; } \\
\text { MUKHOPADHYAY, 2013) }\end{array}$} \\
\hline 4 & $\begin{array}{l}\text { Survey of the following information regarding production time: } \\
\text { daily working day, overtime and working days of each planning } \\
\text { period. }\end{array}$ & \\
\hline 5 & Survey of the rate of production of disaggregated products. & \\
\hline 6 & Calculation of the required capacity of the master production. & \multirow{2}{*}{ (CORRÊA; CORRÊA, 2012) } \\
\hline 7 & Calculation of the installed capacity of the master production. & \\
\hline 9 & Calculation of the loading rate. & (MARTINS; LAUGENI, 2009) \\
\hline 10 & Elaboration of medium-term production capacity plan. & \multirow{2}{*}{$\begin{array}{l}\text { (CORRÊA et al., 2009; JONSSON; } \\
\text { IVERT, 2015; } \\
\text { MUKHOPADHYAY, 2013) }\end{array}$} \\
\hline 11 & Review of the medium-term production capacity plan, if necessary. & \\
\hline
\end{tabular}


DOI: 10.14807/ijmp.v11i2.1067

In the RCCP model, as shown in Figure 6, it is initially defined the disaggregated products and the medium term planning time, according to what was established by the MPS.

Then, the required production capacity is calculated, taking into account the quantity of final products that are described in the production master plan. To make this calculation, it is necessary to have information on two variables relevant to the production process: the rate of production of these products, the amount of labor available and the production master plan that specifies the quantity of production. Additionally, the production process setup times are calculated, taking into account the production stop time of each of the final products planned in the MPS stage.

The description of this model is followed by the consolidation of the installed production capacity, which should take into account the following variables: working days, working hours and overtime, if any.

Finally, for the calculation of the loading rate of the production process for the MPS, which is carried out by the ratio between the total required production capacity and the installed production capacity.

After the completion of this last stage, the medium-term capacity plan for the MPS is issued and, in case of need, it is possible to carry out a review of this plan. After review, the consolidated RCCP plan is issued. As discussed earlier, this information is required for MPS analysis and definition.

The reference model, in BPMN notation, for the RCCP module is shown below, in Figure 6. 
ISSN: 2236-269X

DOI: 10.14807/ijmp.v11i2.1067

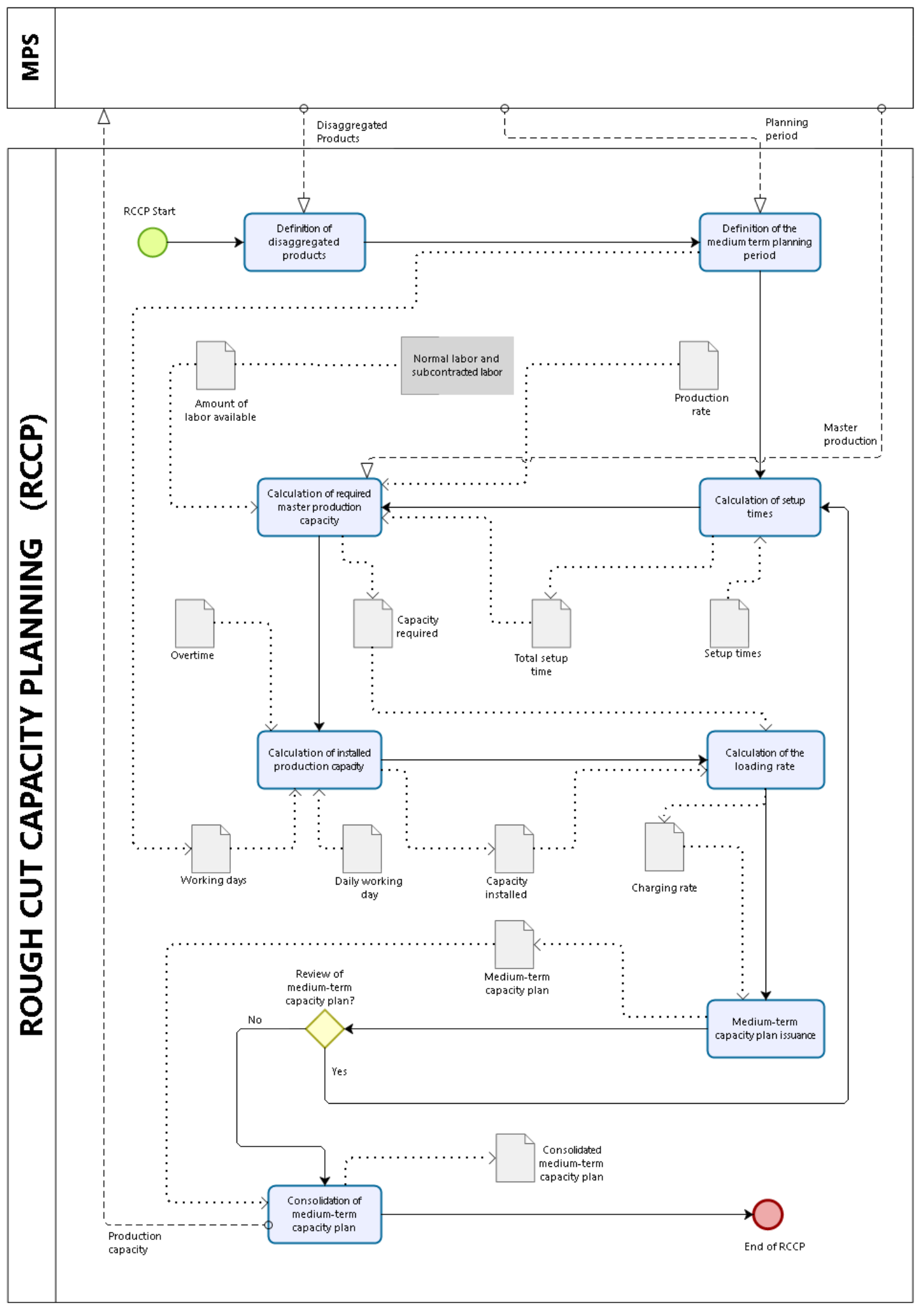

Figure 6: Modeling the RCCP in BPMN.

Source: author. 
ISSN: 2236-269X

DOI: 10.14807/ijmp.v11i2.1067

\subsection{Software prototype}

After the elaboration of the production planning system module for the PPC, the MPS and RCCP module, a software prototype was developed through the Delphi interface, with the intention of generating a greater consistency between the abstraction of the reference model and its application to support the implementation and development of enterprise management tools, a software prototype was developed through the Delphi interface. The first screen of the prototype for MPS and RCCP is being shown in Figure 7.

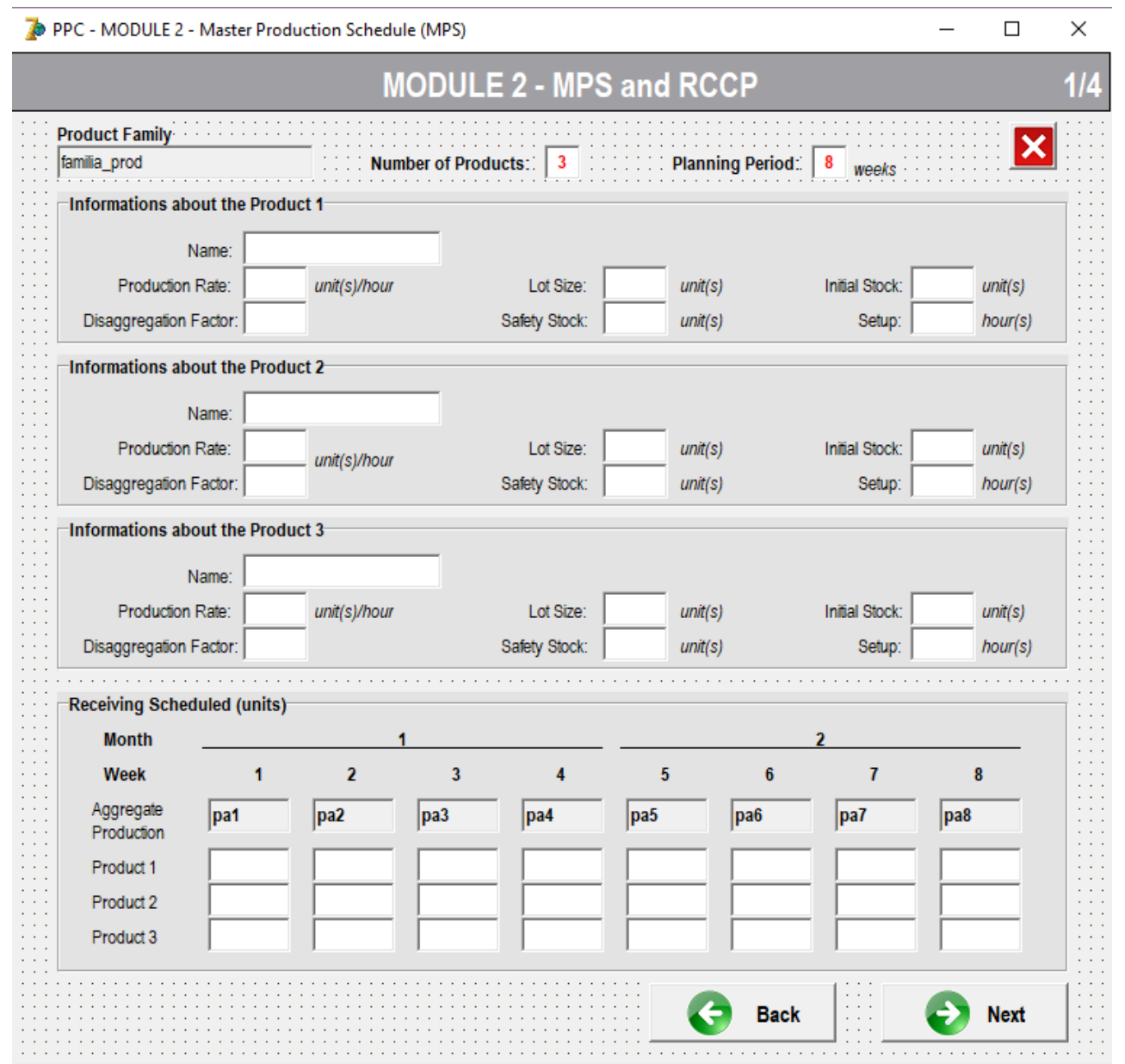

Figure 7: First screen of the PPC software prototype of the MPS and RCCP module. Source: author.

In this screen, the quantities of disaggregated products from the family of products that will participate in the master planning, as well as the period of this medium-term planning, are specified, specifying the final products with their respective production rates, disaggregation factors, lot size production, safety stock, initial stock and setup time. As a convention, it was adopted for the elaboration of this prototype, the planning time of 8 weeks, or 2 months. Likewise, as a limitation for software development, it was decided to establish 3 final products for the master planning. Also in this initial screen, the inputs of the possible programmed 
ISSN: 2236-269X

DOI: 10.14807/ijmp.v11i2.1067

receipts of the final products from, for example, previous planning to the current one are requested.

Figure 8 shows the second screen of the computational program for the MPS and RCCP module.

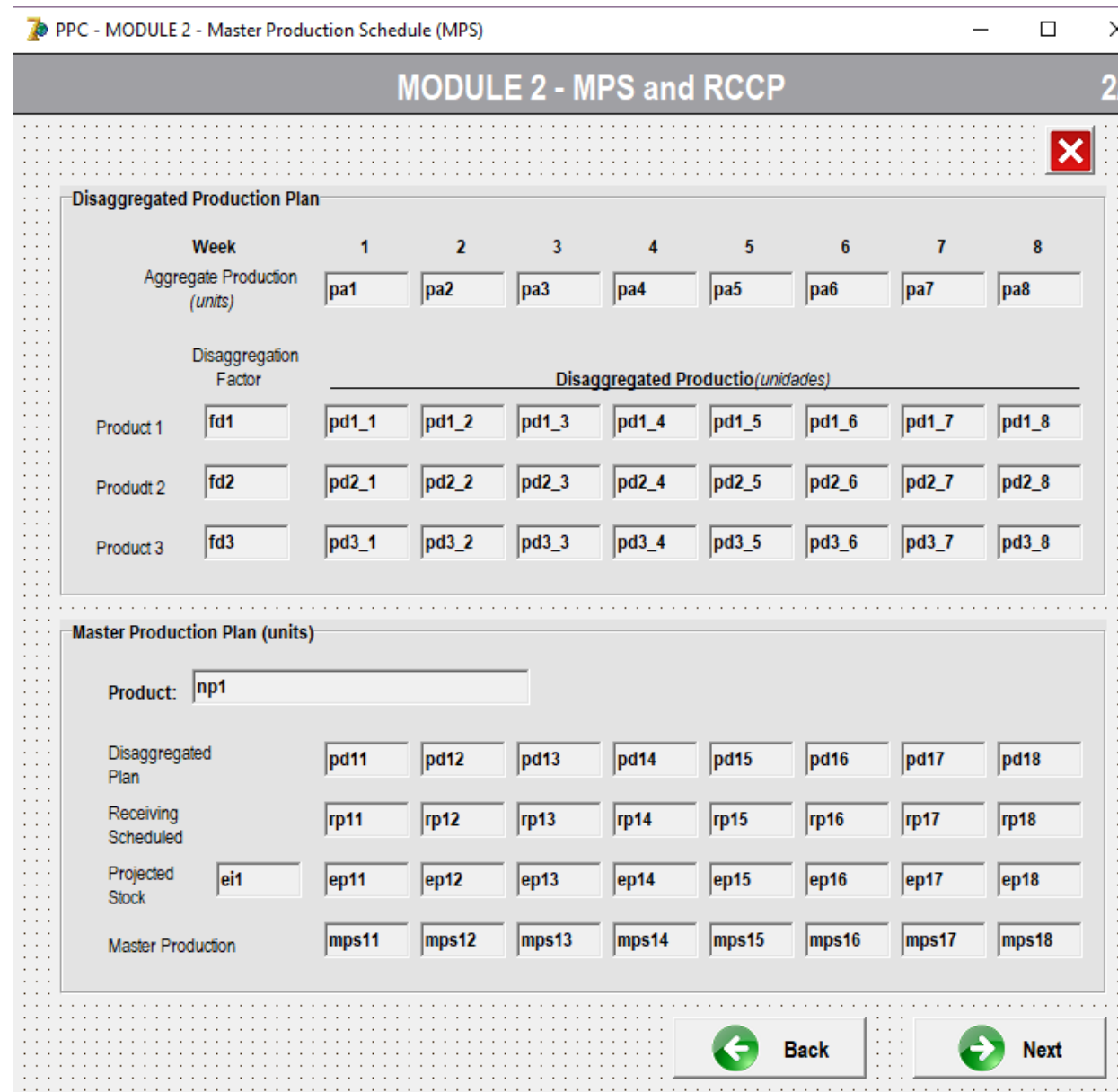

Figure 8: Second screen of the PPC software prototype of the MPS and RCCP module. Source: author.

The monthly production quantities established by S\&OP/AP were stratified (divided) into weeks, ie in this program, each monthly period was divided into 4 weeks. Thus, the disaggregated outputs of each final product are calculated according to the disaggregation factors. At the end of the second screen and the third screen (Figure 9) of the computational program developed from the reference model, the projected inventories and the amount of master production for each final product are calculated over the medium term planning period. 
ISSN: 2236-269X

DOI: 10.14807/ijmp.v11i2.1067

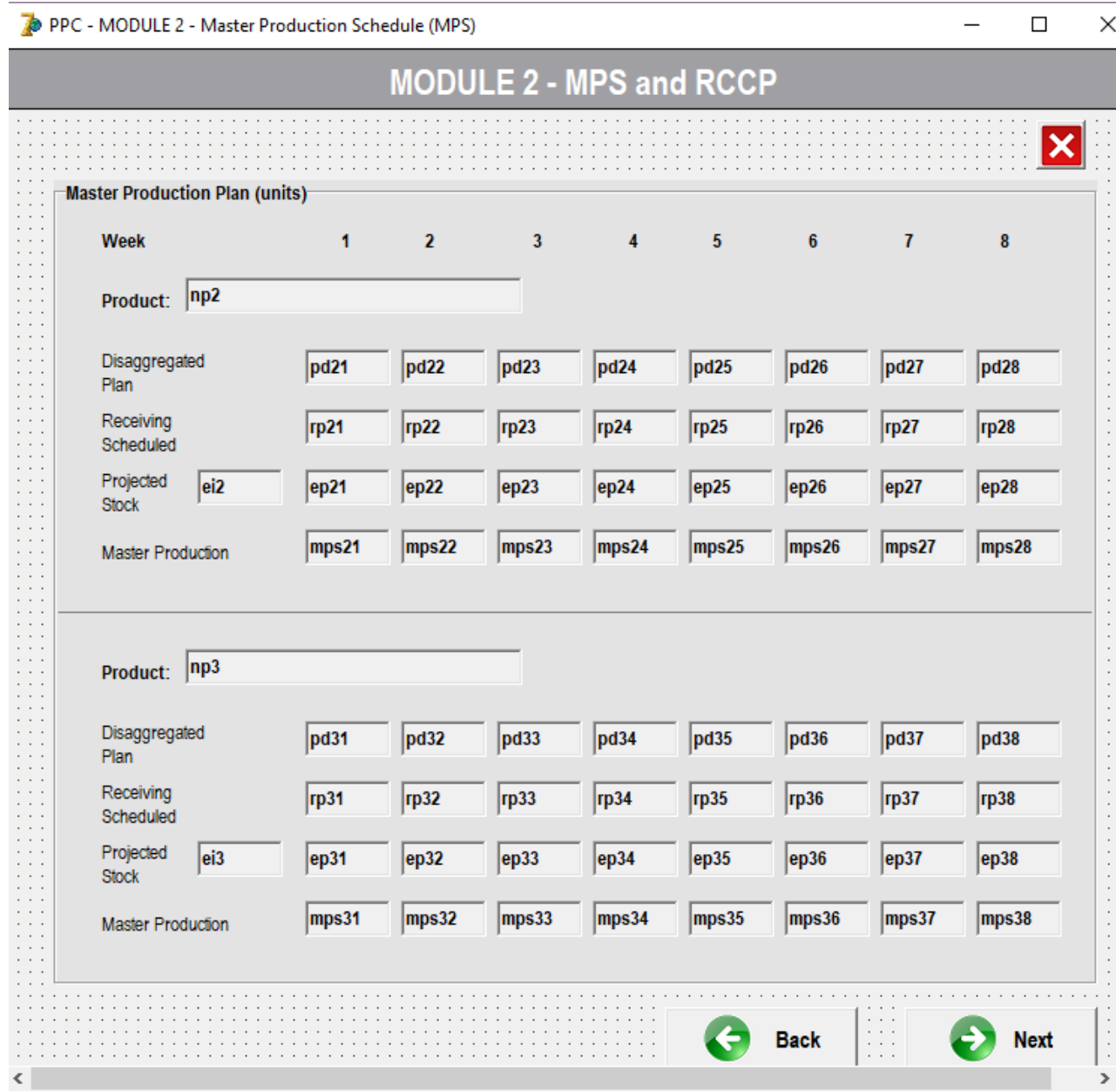

Figure 9: Third screen of the PPC software prototype of the MPS and RCCP module. Source: author.

In the last screen and screen of the PPC software prototype for the MPS and RCCP module, shown in Figure 10, the production and set-up times, in hours, of each of the final products, which will be used for the calculation of the required production capacity. 
ISSN: 2236-269X

DOI: 10.14807/ijmp.v11i2.1067

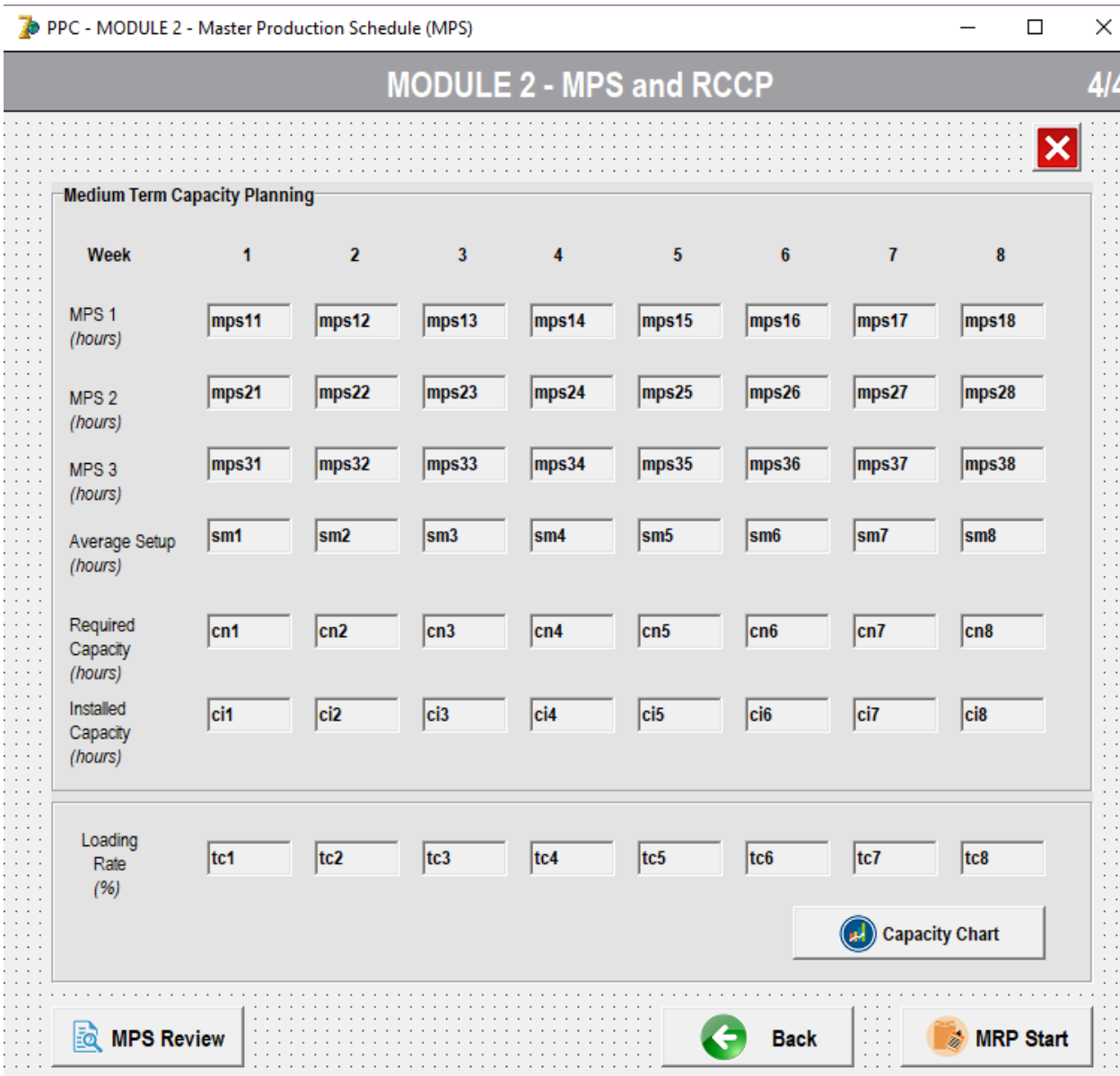

Figure 10: Fourth screen of the PPC software prototype of the MPS and RCCP module. Source: author.

To support the user in viewing the loading rate, with the description of installed and required capacity, this prototype allows the construction of the graph over the medium term planning period, in weeks, as seen in Figure 11.

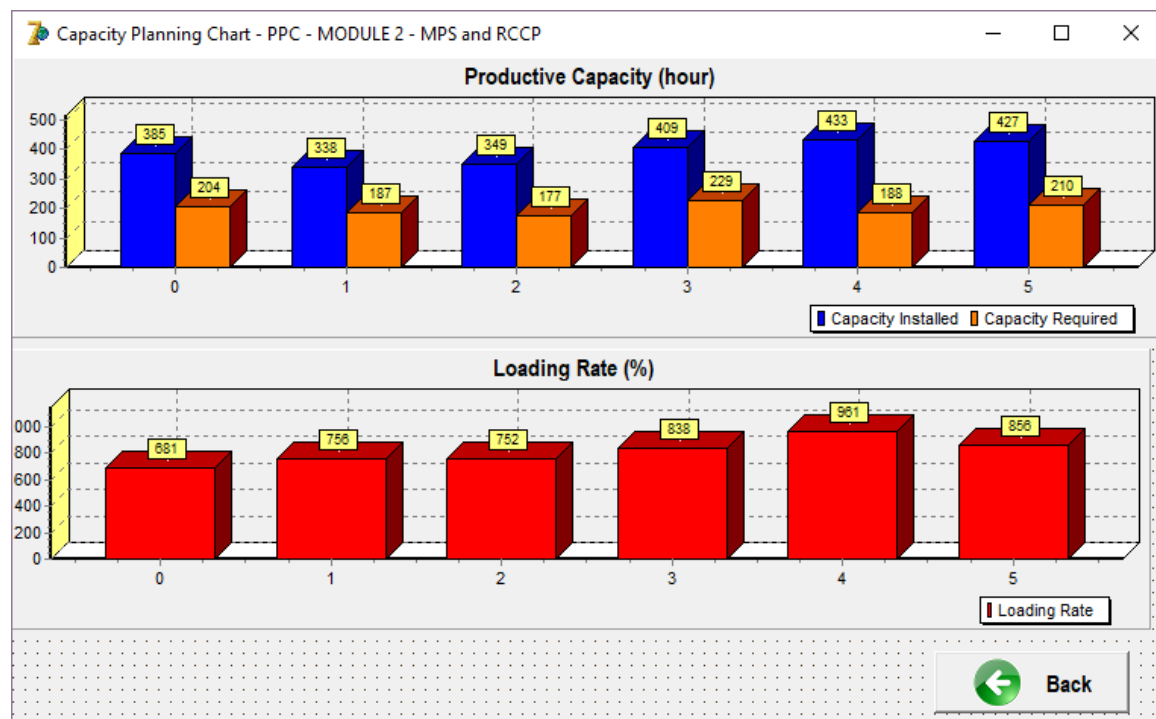

Figure 11: PPC software prototype screen with load rate graph related to MPS module and RCCP.

Source: author. 
INDEPENDENT JOURNAL OF MANAGEMENT \& PRODUCTION (IJM\&P)

http://www.ijmp.jor.br

v. 11, n. 2, March-April 2020

ISSN: 2236-269X

DOI: 10.14807/ijmp.v11i2.1067

In order to validate the software prototype, several tests were carried out, with different planning scenarios and production strategies, in order to verify the activities, information, accuracy and precision of the calculations used to prepare the final master plan.

The results obtained by the computational program were compared with the results extracted manually and in electronic spreadsheets. Thus, the software prototype developed from the developed reference model proved to be reliable and apt to be used for the preparation of production material requirements plans.

\section{CONCLUSION}

Currently, we are seeing increasing attention in the support to the development and implementation of actions of improvements of the business management. However, most research and solutions for production planning are focused on large and complex organizations, highlighting an academic gap regarding work to support the implementation of management systems, especially for small and medium-sized enterprises. Therefore, the reference model developed in this work may provide these companies with an initial solution for their business processes, in order to specify and detail the particular model with a reduction in cost and implementation time.

Thus, this work sought to develop a reference model, in BPMN notation, that addresses the business processes related to MPS, as well as to RCCP, one of the modules inherent in the PPC. In addition, we also aimed to develop a software prototype with the aim of applying this model in systems and management tools.

As a result, from a formal documentation, the reference model proved to be a useful tool in understanding and communicating the existing processes in MPS and RCCP. It was also verified that this developed model is able to support the implantation of production management systems in real situations. However, for use in corporate environments, such as ERP adoption, these processes should receive the expertise and the users should have knowledge of the terms and variables involved in the reference model.

It is worth mentioning that the reference model has been configured as an important tool for knowledge management, since it is capable of storing and documenting existing knowledge in the business processes and serves as a basis for planning the development of new knowledge, always being guided by the strategic objectives of the company.

As a continuation of this work, a model is being developed that approaches in a holistic and hierarchical way the other modules of the Business Processes related to the PPC. Thus, this 
DOI: 10.14807/ijmp.v11i2.1067

reference model seeks to fill gaps in the scientific literature and to advance in relation to international models, since there is a lack of work on reference models for the activities of the PPC.

For the purposes of validation and evaluation, it is suggested the dissemination and application of the software, developed from the reference model, in small and medium-sized enterprises with activities focused on production planning.

\section{REFERENCES}

AS'AD, R.; DEMIRLI, K. (2010) Production scheduling in steel rolling mills with demand substitution: Rolling horizon implementation and approximations. International Journal of Production Economics, v. 126, n. 2, p. 361-369.

BOLLOJU, N.; LEUNG, F. S. K. (2006) Assisting Novice Analysts in Developing Quality Conceptual Models with UML. Commun. ACM, v. 49, n. 7, p. 108-112.

BREMER, C. F.; LENZA, R. DE P. (2000) A reference model for production management in assembly to order: ato production systems and its multiple applications. Gestão \& Produção, v. 7, n. 3, p. 269-282.

CLIMENT, C.; MULA, J.; HERNÁNDEZ, J. E. (2009) Improving the business processes of a bank. Business Process Management Journal, v. 15, n. 2, p. 201-224.

CORRÊA, H. L.; CORRÊA, C. A. (2012) Administração de produção e operações: manufatura e serviços - Uma abordagem estratégica (2nd ed.) São Paulo: Atlas.

CORRÊA, H. L.; GIANESI, I. G. N.; CAON, M. (2009) Planejamento, programação e controle da produção: MRP II/ERP: conceitos, uso e implantação: base para SAP, Oracle Applications e outros Softwares integrados de gestão (5th ed.) Sao Paulo: Atlas.

CORREA, J.; SPINOLA, M. M. (2015) Adoção, seleção e implantação de um ERP livre. Production, v. 25, n. 4, p. 956-970.

ENGLBERGER, J.; HERRMANN, F.; MANITZ, M. (2016) Two-stage stochastic master production scheduling under demand uncertainty in a rolling planning environment.

International Journal of Production Research, v. 54, n. 20, p. 6192-6215.

FERNANDES, F. C. F.; GODINHO FILHO, M. (2010) Planejamento e controle da produção: dos fundamentos ao essencial. São Paulo: Atlas.

GAHM, C.; DÜNNWALD, B.; SAHAMIE, R. (2014) A multi-criteria master production scheduling approach for special purpose machinery. International Journal of Production Economics, n. 149, p. 89-101.

GAITHER, N.; FRAZIER, G. (2005) Administração da produção e operações (8a ed.) São Paulo: Pioneira Thomson Learning.

HERNANDEZ, J. E.; MULA, J.; FERRIOLS, F. J. (2008) A reference model for conceptual modelling of production planning processes. Production Planning and Control, v. 19, n. 8, p. 725-734.

HERRERA, C.; BELMOKHTAR-BERRAF, S.; THOMAS, A.; PARADA, V. (2016) A reactive decision-making approach to reduce instability in a master production schedule. International Journal of Production Research, v. 54, n. 8, p. 2394-2404. 
JONSSON, P.; IVERT, L. K. (2015) Improving performance with sophisticated master production scheduling. International Journal of Production Economics, v. 168, n. Supplement C, p. 118-130.

KELLER, G.; TEUFEL, T. (1998) SAP R/3 process-oriented implementation: iterative process prototyping. Harlow, England; Reading, Ma: Addison Wesley Longman.

LALAMI, I.; FREIN, Y.; GAYON, J. P. (2015) A model for master production scheduling in automotive powertrain plants: A case study. In 2015 International Conference on Industrial Engineering and Systems Management (IESM) (p. 1081-1090)

MARTINS, P. G.; LAUGENI, F. P. (2009) Administração da produção. São Paulo: Saraiva.

MOREIRA, D. A. (2008) Administração da produção e operações. São Paulo: Cengage Learning.

MUKHOPADHYAY, S. K. (2013) Production planning and control: text and cases (2. ed) Delhi: PHI Learning.

OLHAGER, J. (2013) Evolution of operations planning and control: from production to supply chains. International Journal of Production Research, v. 51, n. 23-24, p. 68366843.

OLHAGER, J.; RUDBERG, M.; WIKNER, J. (2001) Long-term capacity management: Linking the perspectives from manufacturing strategy and sales and operations planning. International Journal of Production Economics, v. 69, n. 2, p. 215-225.

SAHIN, F.; POWELL ROBINSON, E.; GAO, L.-L. (2008) Master production scheduling policy and rolling schedules in a two-stage make-to-order supply chain. International Journal of Production Economics, v. 115, n. 2, p. 528-541.

SCHEER, A.-W. (2000) ARIS - Business Process Frameworks (3rd ed.) Berlin, Heidelberg: Springer Berlin Heidelberg.

SIAU, K. (2004) Informational and Computational Equivalence in Comparing Information Modeling Methods. Journal of Database Management (JDM), v. 15, n. 1, p. 73-86.

SIAU, K.; ROSSI, M. (2011) Evaluation techniques for systems analysis and design modelling methods - a review and comparative analysis. Information Systems Journal, v. 21, n. 3, p. 249-268.

TEO, C.-C.; BHATNAGAR, R.; GRAVES, S. C. (2012) An Application of Master Schedule Smoothing and Planned Lead Time Control. Production and Operations Management, v. 21, n. 2, p. 211-223.

THURER, M.; FILHO, M. G. (2012) Redução do lead time e entregas no prazo em pequenas e médias empresas que fabricam sob encomenda: a abordagem Worload Control (WLC) para o Planejamento e Controle da Produção (PCP), Gestão \& Produção, n. 19.

TUBINO, D. F. (2007) Planejamento e controle da produção teoria e prática. São Paulo: Atlas.

VERGIDIS, K.; TURNER, C. J.; TIWARI, A. (2008) Business process perspectives: Theoretical developments vs. real-world practice. International Journal of Production Economics, v. 114, n. 1, p. 91-104.

VERNADAT, F. (1996) Enterprise modeling and integration: principles and applications. London; New York: Chapman \& Hall. 
VERNADAT, F. B. (2003) Enterprise Modelling and Integration. In KOSANKE, K.; JOCHEM, R.; NELL, J. G.; BAS, A. O. (Eds.; p. Enterprise Inter- and Intra-Organizational Integration (pp. 25-33) Boston, MA: Springer US.

VIEIRA, G. E.; FAVARETTO, F. (2006) A new and practical heuristic for Master Production Scheduling creation. International Journal of Production Research, v. 44, n. 18-19, p. 3607-3625.

VOJISLAV, B.; LEON, J. (2000) Evaluating the Quality of Reference Models. In Conceptual Modeling — ER 2000 (p. 484-498) Springer, Berlin, Heidelberg.

VOLLMANN, T. E. (ED.) (2005) Manufacturing planning and control for supply chain management (5th ed) Boston: McGraw-Hill/Irwin.

WATTANAPORNPROM, W.; LI, T. (2013) The merging of MPS and order acceptance in a semi-order-driven industry: A case study of the parasol industry. In 2013 IEEE

International Conference on Industrial Engineering and Engineering Management (p. 996-1001) 